\section{SM Tropical Medicine Journal}

\section{Article Information}

Received date: Aug 04, 2017

Accepted date: Aug 30, 2017

Published date: Sep 04, 2017

\section{*Corresponding author}

Yaseer Muhammad Tareq Khan, Ibri Regional Hospital, Ibri 352, Sultanate of Oman, Tel: +96892401869;

Email: tareq_doc2001@yahoo.com

Distributed under Creative Commons CC-BY 4.0

Keywords Snake bite; Envenomation; Oman; Coagulopathy; Anti-snake venom Article DOI 10.36876/smtmj.1015

\section{OPEN ACCESS}

\section{Snake Bite Envenomation: Experience in a Regional Hospital, Oman: A Retrospective Observational Study}

\author{
Yaseer Muhammad Tareq Khan ${ }^{1 \star}$, Nishat Fatema ${ }^{2}$ and Nasser Abdullah Al \\ Shekeili ${ }^{1}$ \\ ${ }^{1}$ Department of Internal Medicine, Ibri Regional Hospital, Sultanate of Oman \\ ${ }^{2}$ Department of Obstetrics \& Gynaecology, Ibri Regional Hospital, Sultanate of Oman
}

\section{Abstract}

Background: The present study is a retrospective review of snakebite envenomation in a regional hospital in Oman, over a period of 6 years from January 2011 to December 2016

Objective: To evaluate the frequency of snake bite, their clinical characteristics, outcome and management.

Methodology and results: We carried out a retrospective observational study of a total of 83 cases of snakebites. There was no difference in the frequency of bite between Omani (48.2\%) and non-Omani $(51.8 \%)$ patients. The majority $(84.3 \%)$ of the victims were male. Most of the bites (53\%) happened in farm areas, particularly at morning and evening with $34.9 \%$ and $33.7 \%$ respectively. The common site of bite was lower $(55.4 \%)$ and upper $(43.4 \%)$ limbs; $68.7 \%$ of the patients had abnormal coagulation profile. During discharge, $92.8 \%$ patients had normal coagulation profile. Among four patients of acute kidney injury, one patient required hemodialysis and subsequently developed chronic kidney disease. During the study period no death observed as a result of snakebite. We observed the frequency of snakebite increased yearly and a sharp rise in 2016 with the rate of $49.40 \%$. Most bites were occurred in between May and October, where the maximum peak noticed in the month of May and August with $16.9 \%$ and $18.1 \%$ respectively. Polyvalent Anti-Snake Venom (ASV), tetanus toxoid and antibiotics were used as a part of management.

Conclusion: The reason behind the increased number of victims is negligence among occupational workers while working in snake-infested areas. So, increase awareness is necessary to reduce the incidence of snake bite by educating people about proper safety measures and in turn to minimize the patients suffering and treatment cost at personal and as well as government level.

\section{Introduction}

Globally, snake bite envenomation is considered as a major medical problem, but this clinical condition is neglected in rural areas of tropical parts of the world and not frequently discussed in the literature due to insufficient data and information. The incidence of snakebite in regional areas is not clear [1].

Approximately $30 \%$ of the 3000 snakes across the world are found to be venomous and dangerous to human [2]. The annual number of snake-bite envenomations is estimated at 2.5 million victims a year. Reported numbers of deaths vary, ranging from 20,000 to 125,000 [3-5].

Snake bite envenomation is commonly observed in poor and rural communities, and the burden of treatment cost is reported highest in and Sub-Saharan Africa and South and Southeast-Asia [6].

Due to lack of adequate studies, snakebite envenomation is not a reportable condition, so the accurate incidence of snakebite is unknown in Oman. The most common venomous snakes in the Middle East are vipers (Cerastesgasparetti, Echiscarinatus, Echiscoloratus and Pseudocerastespersicus) and non-vipers, mainly Colubridae, Atractaspididae and Elapidae species (reference). Among nine venomous terrestrial snakes, $9 \%$ of snakebites in Oman are caused by the Saw-scaled Viper (Echiscarinatus), which usually is found in the rocky areas. Other related species, such as the Burton's carpet snake (Echiscoloratus) of hilly regions or the Horned Viper (Cerastesgasperettii) of the deserts, are responsible for approximately $9 \%$ of bites. These three types of vipers have broad heads with two-hinged fangs whose venom causes coagulopathy. The main species of venomous snake in the north of Oman are E. carinatussochureki and E. omanensis [6,7]. Both of these cause Venom-Induced Consumption Coagulopathy (VICC), activation of the clotting pathway by prothrombin activator toxins, and consumption of clotting factors (fibrinogen, factor $\mathrm{V}$ and factor VIII) which lead to a consumptive coagulopathy. Clinical signs include spontaneous bleeding due to damage of the blood vessels and subsequently hypovolaemic shock to secondary organ damage, such as intracerebral haemorrhage, anterior pituitary haemorrhage or renal damage [8,9]. 
Snakebite envenomation may cause different clinical features, depending on the involved snake species. Such as family Viperidae (C. c. gasperettii and E. coloratus) causes hematological toxicity, which can be manifested through bleeding that, may develop into coagulopathy [2].

Hemorrhage, coagulation impairment, hemolysis and general cardiovascular disturbances are mainly developed due to hematological involvement following snakebite. Other serious symptoms are also reported that involves physiological and metabolic changes [10].

Ibri is located in the northern part of Oman under Al Dhahira governorate. The total area size of $\mathrm{Al}$ Dahirah is $37,000 \mathrm{~km}^{2}$, and the population, according to the 2010 census, is 151,664. Ibri Regional hospital is the only secondary care regional hospital of this governorate, and all referral cases are accepted in this hospital from its catchment areas. The two main catchment areas are Yanqul and Dhank [11].

The climate of Ibri is hot and dry. This type of weather may create a favorable site for snake habitat. Agricultural and farm workers are the common group of people who have experienced snakebite commonly in this area [6]. Most bites were due to negligence of people working on farms or in date gardens. We observed the rate of snakebite over our study period sharply increased over the time period of this study.

\section{Objectives}

We carried out a retrospective observational study in a regional hospital to determine the frequency of snakebite, their clinical characteristics, outcome and management. We aim to increase awareness by educating people about proper safety measures and in turn to minimize the patients suffering.

\section{Materials and Methods}

In this retrospective observational study, we evaluate all snakebite cases admitted in the Department of Internal Medicine of Ibri Regional Hospital over a six-year period from January 2011 to December 2016. Patient's hospital records were obtained from the computerized medical registry of Ibri Regional Hospital. The selection criterion of the patient was made using the final diagnosis of "snake venom" in the medical records. We also examined records for whether the patient had seen the snake during the bite or if the bite was clinically proved bite by a physician. All other insect stings, reptile bites, or confusing cases where victims did not see the snake during bite or could not otherwise be proved as snakebite were excluded from the study.

All relevant and clinical information of cases were extracted from hospital electronic records. Demographic criteria of patients (age, sex, gender, race), snake bite-related information (time of bite, place of bite, site of bite) and laboratory investigations are included in data collection.

Patients were initially evaluated in accident emergency after being referred or escorted from local health centers. Physician did further evaluation, and an admission was made to the internal medicine department for management.

All patients were managed according to national protocol (Figure 1) by administration of polyvalent snake anti-venom (Tradename,
National Antivenom and Vaccine Production Center National Guard Health Affairs, Riyadh, Saudi Arabia). The antivenom is effective to neutralize the toxin of Bitisarietans, Cerastescerastes, E. coloratus, E. carinatus, Najahaje and Walterinnesiaaegyptia but also can neutralize other species as Bitiscaudalis, Bitisgabonica, Najanigricollis, Najanaja, Najamelanleuca due to the phylogenetic aspects of toxin production [6].

Doses of anti-snake venom for patients were adjusted according to severity and laboratory findings of coagulation profile. Coagulopathy was defined as having prolonged prothrombin time (PT; normal range 12.8-16.1) and activated partial thromboplastin time (APTT; normal range 24.8-37.4). Tetanus toxoid, and antibiotic prophylaxis was given as part of supportive management. After normalization of coagulation, profile patients were discharged, except those who went against medical advice (LAMA).

For all analysis, Statistical Package for the Social Sciences Software (SPSS) Mac version 23.0 was used. Quantitative data with normal distribution was expressed as mean $\pm \mathrm{SD}$; otherwise median and range were used. For qualitative data frequency and Chi square (cross tabulation) test was used for the analysis. P value $<0.05$ ( 2 sided) is considered as statistically significant.

Ethical approval was taken from the Regional Ethical Committeereference number MH/DGHS/DG/886/16.

\section{Results}

A total of 83 cases of snakebites were studied over a six-year period from January 2011 to December 2016. The demographic characteristics of the patients were listed in Table 1 . The majority (84.3\%) of the victims were male. Patient's mean age was $35 \pm 15$ years. There was no difference in the overall frequency of bite between Omani (48.2\%) and non-Omani (51.8\%) patients but after 2013 we observed that the non omani populations are more effected than Omani group (Table 2). Most of the bites (53\%) happened at farm areas particularly at morning and evening with $34.9 \%$ and $33.7 \%$ respectively. Only $21.7 \%$ of patients were bitten at night. The most common site of bites was lower (55.4\%) and upper (43.4\%) limbs. Though some of the patients brought the killed snake (Figure 2) with them, the identity of the snake was not described. In addition, $90.4 \%$ of patients presented to hospital accident and emergency department between one and five hours of snakebite.

Pain (97.6\%) at the bite site was the most common presenting symptom. Seventy one (85.5\%) patients had local swelling in bite site. Twelve percent of patients had vomiting at presentation. Four patients had non-significant bleeding - among them two patients had hemoptysis, one patient had haematemesis, and the other had gum bleeding. Only one patient had fever. A fang mark was identified in $69(83.1 \%)$ patients. Though one patient had skin blistering, none of the patients had neurotoxicity or shock (Table 3 ).

At presentation, 57 (68.7\%) of the patients had abnormal coagulation profile. During discharge, $92.8 \%$ patients had normal coagulation profile and the rest were discharged by left against medical advice with abnormal coagulation profile and lost follow up. The mean hemoglobin was $14.3 \pm 1.9$ and 19 (22.9\%) patients had leukocytosis. Only one patient had developed local hematoma on bite site and which required surgical exploration. One case had allergic reaction upon receiving antivenom. Two patients had readmission 


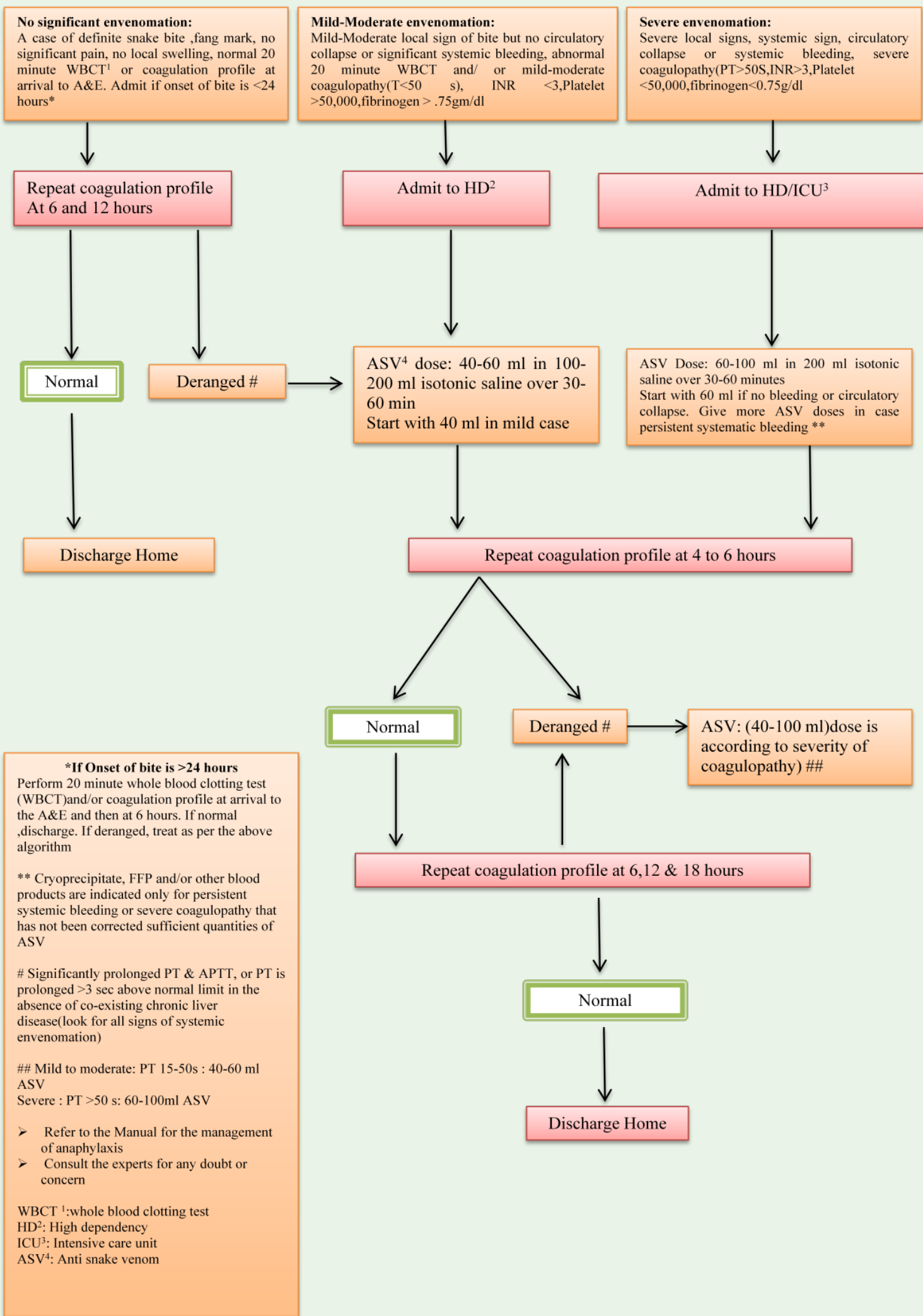

Figure 1: National protocol for the management of haemotoxic snake bite.

Citation: Khan YMT, Fatema N and Shekeili NAA. Snake Bite Envenomation: Experience in a Regional Hospital, Oman: A Retrospective Observational Study. SM Trop Med J. 2017; 2(1): 1015 
Table 1: Demographic Characteristics.

\begin{tabular}{|c|c|c|}
\hline Demography & $n=83$ & $\%$ \\
\hline \multicolumn{3}{|l|}{ Age (year) } \\
\hline Mean $\pm S D$ & $35 \pm 15$ & \\
\hline Min-Max & $14-85$ & \\
\hline \multicolumn{3}{|l|}{ Sex } \\
\hline Male & 70 & 84.3 \\
\hline Female & 13 & 15.7 \\
\hline \multicolumn{3}{|l|}{ Race } \\
\hline Omani & 40 & 48.2 \\
\hline Non-Omani & 43 & 51.8 \\
\hline \multicolumn{3}{|l|}{ Site of bite } \\
\hline Upper limb & 36 & 43.4 \\
\hline Lower limb & 46 & 55.4 \\
\hline Others & 1 & 1.2 \\
\hline \multicolumn{3}{|l|}{ Time of bite } \\
\hline Morning & 29 & 34.9 \\
\hline Afternoon & 8 & 9.6 \\
\hline Evening & 28 & 33.7 \\
\hline Night & 18 & 21.7 \\
\hline \multicolumn{3}{|l|}{ Place of bite } \\
\hline Farm & 44 & 53 \\
\hline Others & 39 & 47 \\
\hline \multicolumn{3}{|c|}{ Time interval between bite and arrival to hospital } \\
\hline$<1$ hour & 2 & 2.4 \\
\hline $1-5$ hours & 75 & 90.4 \\
\hline$>5$ hours & 6 & 7.2 \\
\hline \multicolumn{3}{|l|}{ During Bite snake } \\
\hline Seen & 72 & 86.7 \\
\hline Not seen & 11 & 13.3 \\
\hline
\end{tabular}

due to persistent swelling and pain and were managed conservatively. Four patients had acute kidney injury; two of them recovered fully with fluid management, one patient left against medical advice and lost follow-up, and one patient required hemodialysis and subsequently developed chronic kidney disease. In total, 67 (80.7\%) cases had received antivenom among them; 57 (68.7\%) cases had deranged coagulation and the rest 10 patients received stat dose of antivenom empirically during admission. The median of the antivenom dose was $200 \mathrm{ml}$ (IQR=40-260). As a supportive treatment antibiotic (Inj. Amoxiclav) and tetanus toxoid was received $86.7 \%$ and $47 \%$ respectively. Hospital admission required maximum of five days with $2.3 \pm 0.9($ mean \pm SD) (Table 3$)$.

During our study period, the rate of snakebite increased yearly and observed a sharp rise in 2016 with the rate of $49.40 \%$ (Figure 3). We observed the most bite was occurred in between May-October

Table 2: Frequency of snakebite in Omani and Non-Omani Population (Yearly).

\begin{tabular}{|c|c|c|c|c|}
\hline Year & \multicolumn{2}{|c|}{ Omani } & \multicolumn{2}{c|}{ Non- Omani } \\
\hline 2011 & 3 & 100 & 0 & 0 \\
\hline 2012 & 3 & 100 & 0 & 0 \\
\hline 2013 & 5 & 71 & 2 & 29 \\
\hline 2014 & 1 & 10 & 9 & 90 \\
\hline 2015 & 4 & 21 & 15 & 79 \\
\hline 2016 & 10 & 24 & 31 & 76 \\
\hline
\end{tabular}

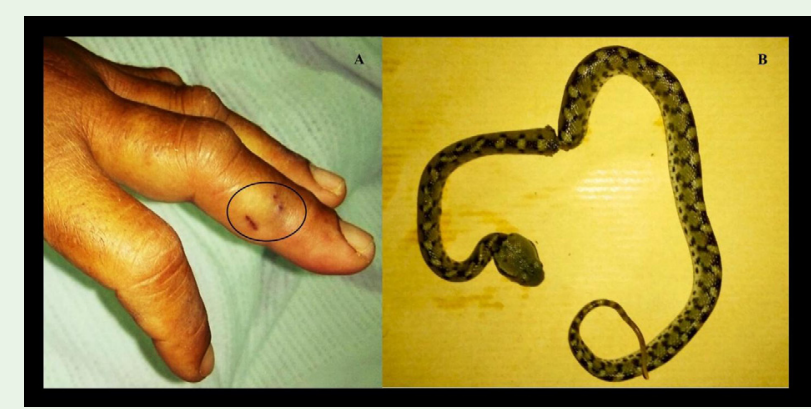

Figure 2: (A)-Snakebite on the finger (B)- Killed snake.

Table 3: Snake bite related data.

\begin{tabular}{|c|c|c|}
\hline Snake Bite Related Data & $n=83$ & $\%$ \\
\hline \multicolumn{3}{|l|}{ Symptoms } \\
\hline Pain & 81 & 97.6 \\
\hline Swelling & 71 & 85.5 \\
\hline Vomiting & 10 & 12 \\
\hline Fever & 1 & 1.2 \\
\hline Bleeding & 4 & 4.8 \\
\hline
\end{tabular}

Sign

\begin{tabular}{|c|c|c|}
\hline Fang mark seen & 69 & 83.1 \\
\hline Skin discoloration & 18 & 21.7 \\
\hline Neurological deficit /Shock & nil & \\
\hline Laboratory & \multicolumn{2}{|c|}{} \\
\hline Coagulopathy & 57 & 68.7 \\
\hline Normal coagulation during discharge & 77 & 92.8 \\
\hline Haemoglobin (Mean \pm SD) & $14.3 \pm 1.9$ & \\
\hline Leukocytosis & 19 & 22.9 \\
\hline Renal function & & \\
\hline Normal & 79 & 95.2 \\
\hline deranged & 4 & 4.8 \\
\hline
\end{tabular}

Complications

\begin{tabular}{|c|c|c|}
\hline Local haematoma & 1 & 1.2 \\
\hline Allergy to anti snake venom & 1 & 1.2 \\
\hline Blister formation & 1 & 1.2 \\
\hline haematemesis & 1 & 1.2 \\
\hline haemoptysis & 2 & 2.4 \\
\hline readmission & 2 & 2.4 \\
\hline Acute kidney injury & 4 & 4.8 \\
\hline
\end{tabular}

Treatment

\begin{tabular}{|c|c|c|}
\hline Anti-snake venom received & 67 & 80.7 \\
\hline \multicolumn{2}{|l|}{ Dose of ante snake venom (ml) } & \\
\hline Median (IQR) & $200(40-260)$ & \\
\hline Antibiotic received & 72 & 86.7 \\
\hline \multicolumn{3}{|l|}{ Tetanus toxoid } \\
\hline Received & 39 & 47 \\
\hline No record & 44 & 53 \\
\hline \multicolumn{2}{|l|}{ Hospital stay (days) } & \\
\hline Min-maximum & 5-Jan & \\
\hline (Mean $\pm S D)$ & $2.3 \pm 0.9$ & \\
\hline \multicolumn{3}{|l|}{ Discharge } \\
\hline Discharge after treatment & 72 & 86.7 \\
\hline Left against medical advice & 11 & 13.3 \\
\hline
\end{tabular}

Citation: Khan YMT, Fatema N and Shekeili NAA. Snake Bite Envenomation: Experience in a Regional Hospital, Oman: A Retrospective Observational Study. SM Trop Med J. 2017; 2(1): 1015.

https://dx.doi.org/10.36876/smtmj.1015 


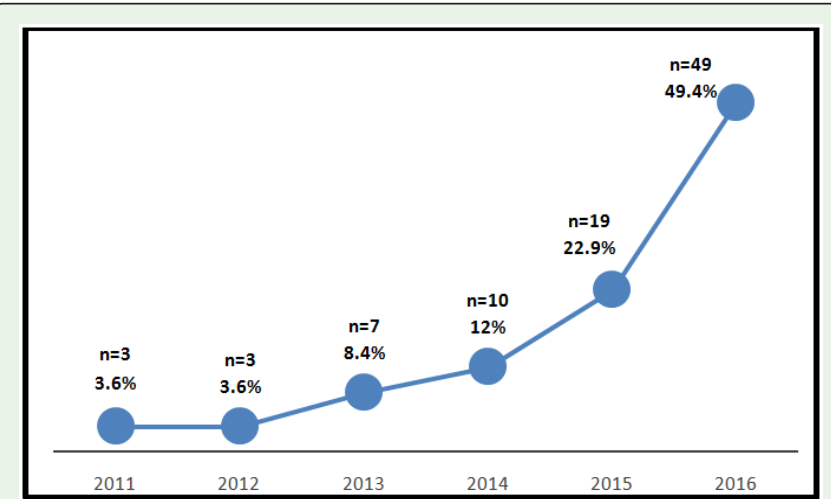

Figure 3: Frequency of snakebite from 2011-2016 (n=83).

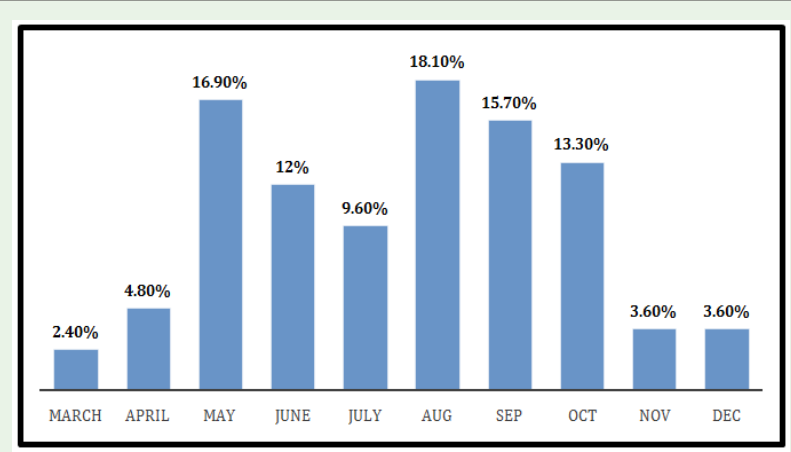

Figure 4: Frequency of snakebite during different months (2011-2016)

where the maximum peak noticed in the month of May and August $16.9 \%$ and $18.1 \%$ respectively. There was no reported case of snakebite seen in the month of January and February during our study period (Figure 4).

\section{Discussion}

In our study, the majority of patients were male (84.3\%), and more than half of the cases suffered a snake bite while working in farm areas. This variation can be explained as most females spend their time at indoor activities whereas males are working in outdoor and farm areas [2]. Another study also observed a significant difference in the male-female victim ratio of approximately 9:112.

Most of the snakebite victims in our study were young adults with an average mean age of 35 years. In a study in Oman, they observed male patients aged 21-30 year were the victim of snake bite envenomation, and most had been bitten during irrigation time while working in farm or field and the maximum bite was observed in the evening time [7]. In our study, we observed that bite occurred in morning (34.9\%) and evening (33.7\%) time was not statistically different.

The most common site of snake bite was in the limbs. Forty six (55.4\%) cases had got the bite in lower limb and 36 (43.4\%) patients in the upper limb. Only one patient had bite on the scalp that occurred while sleeping. Our results are similar to other studies which found that the exposed parts of body especially limbs are the common sites of snake bite due to lack of protective measures for foot and hands like footwear and gloves $[2,6]$.
Most of the patients (90.4\%) reported to accident and emergency within 1-5 hours of snakebite. Only six cases had delayed presentation because some of them had the lack of transportation or some of them were from a far place. As most of the patients reached the hospital within an acceptable time frame, we didn't observe any deleterious complications in the patients. A multi-centered study in the Middle East also observed most of the patients reaching the A\&E within three hours of bite [6].

Although most patients reported to the hospital within the acceptable time for seeking medical management, we observed sharp rise in snakebites during our study period, which reached the maximum in 2016 (49.40\%), shown in chart [3]. The reason behind this increased frequency of snakebite might be negligence among victims working in farming areas and date gardens without taking protective measures (Table 3 ).

No snakebite cases were reported in the months of January and February during our study period. The majority of the snakebite cases were reported during the summer season (May-October) with the highest incidence observed in the month of August. This may be due to the snakes hibernating or becoming inactive during the winter season in lowered ambient temperature. Al-Saddon et al. also observed that the frequency of snake bite is higher during summer months with the maximum peak in August in the Riyadh province of Saudi Arabia [2].

The majority of the victims were presented with local swelling and pain $97.6 \%$ and $85.5 \%$ respectively. None of the patients were observed with shock, loss of consciousness or with compartment syndrome. On the basis of laboratory findings, coagulopathy was the main manifestation (68.7\%). A similar study by H. Al-Durihim, they detected coagulopathy among $66.7 \%$ cases [12]. Viperide snakes release toxin haemorrhagins that act to increase vascular permeability or damage the vascular endothelium. Many of these toxins are zinc metalloproteinases and can cause pathologic bleeding or more severe local effects in the bitten limb. The procoagulant enzymes in certain viper venoms (carpet or saw scaled vipers) causes coagulopathy and the presence of haemorrhagins in the venom accelerate the effects of procoagulants [9].

Leukocytosis was found among 19 (22.9\%) patients and four patients had acute kidney injury. Among four patients of acute kidney injury, three of them recovered fully but one patient had developed chronic kidney disease because of snakebite and required dialysis.

One patient developed local hematoma at the bite site, which required surgical exploration. One case reported with allergic reaction upon receiving anti-snake venom, two patients had were re-admitted for persistent swelling and pain, one patient had haematemesis, another two patients observed with hemoptysis and was managed conservatively.

Overall, 67 (80.7\%) cases had received anti snake venom among them $57(68.7 \%)$ cases had deranged coagulation and the rest of the 10 patients received stat dose of antivenom empirically during admission. The median of the anti-snake venom dose was $200 \mathrm{ml}$ (IQR=40-260). Prophylactic antibiotics were given to $72(86.7 \%)$ cases. Routine prophylactic use of antibiotics is common in our hospital though this practice is not an established practice for the management of snakebite according to the previous studies $[13,14]$. 
This is probably as a consequence of the lack of a clearly defined policy with regards to the exact role of antibiotics in the management of snakebite in Oman.

The maximum hospital stay was recorded five days with mean $2.3 \pm 0.9$ days. $86.7 \%$ of patients were discharged after complete recovery. Eleven (13.3 \%) cases went against medical advice before normalization of coagulation and other symptoms due to financial reason.

\section{Limitation}

The retrospective analysis and small study population are our study limitation.

\section{Conclusion}

The majority of cases reported to hospital within an acceptable time frame after snakebite for medical advice without taking any local traditional management. We observed that the annual rate of venomous snakebite increased sharply. The reason behind the increased number of victims is negligence in occupational worker, especially in the non-Omani population, who are not aware of using preventive measures while working in snake-infested areas.

Implementation of proper health education schemes can play the main role in the success of preventative measures. Increase awareness among the people is important that the risk of snakebite is greater during the summer season of the year. Farm workers should be educated about using footwear and gloves while working in snakeinfested areas. Education of emergency medical staff is necessary for the identification of venomous snakebites to take a proper step in the treatment $[2,10]$. Compulsory reporting of snakebites at local, regional and national levels would improve data collection for future analysis. This may assist in minimizing affected patients' suffering and treatment cost at the personal as well as at the governmental level.

\section{References}

1. Ismail M, Memish ZA. Venomous snakes of Saudi Arabia and the Middle East: a keynote for travellers. Int J Antimicrob Agents. 2003; 21: 164-169.

2. Al-Sadoon MK. Snake bite envenomation in Riyadh province of Saudi Arabia over the period (2005-2010). Saudi J Biol Sci. 2015; 22: 198-203.

3. Swaroop S. SNAKEBITE MORTALITY IN THE WORLD. Bull Org mond Sante Bull WId HIth Org. 1954; 10: 35-76.

4. Snake bite and snake venoms.

5. Chippaux JP. Snake-bites: appraisal of the global situation. Bulletin of the World Health Organization. 1998; 76: 515-524.

6. Alkaabi JM, Al Neyadi M, Al Darei F, Al Mazrooei M, Al Yazedi J, Abdulle AM. Terrestrial snakebites in the South East of the Arabian Peninsula: patient characteristics, clinical presentations, and management. PLoS One. 2011; 6: e24637.

7. Al-Lawati A, Al-Abri SS, Lalloo DG. Epidemiology and outcome of snake bite cases evaluated at a Tertiary Care Hospital in Oman. J Infect Public Health. 2009; 2: 167-170.

8. Isbister GK, Brown SGA, Page CB, McCoubrie DL, Greene SL, Buckley NA. Snakebite in Australia: a practical approach to diagnosis and treatment. Med J Aust. 2013; 199: 763-768.

9. White J. Snake venoms and coagulopathy. Toxicon. 2005; 45: 951-967.

10. Haidar NA, Deitch E. Snake bites in the Arabian Peninsula, a review article. J Arid Environ. 2015; 112: 159-164.

11. Ad Dhahirah Governorate - Wikipedia.

12. Al-Durihim H, Al-Hussaini M, Bin Salih S, Hassan I, Harakati M, Al Hajjaj A. Snake bite envenomation: experience at King Abdulaziz Medical City, Riyadh. East Mediterr Health J. 2010; 16: 438-441.

13. Kerrigan KR, Mertz BL, Nelson SJ, Dye JD. Antibiotic prophylaxis for pit viper envenomation: prospective, controlled trial. World J Surg. 1997; 21: 369-372.

14. Tagwireyi DD, Ball DE, Nhachi CF. Routine prophylactic antibiotic use in the management of snakebite. BMC Clin Pharmacol. 2001; 1: 4 